\title{
Milk Leucocyte Population Patterns in Bovine Udder Infection of Different Aetiology
}

\author{
G. Leitner ${ }^{1,3}$, E. ShOSHANi ${ }^{2}$, O. KRIFuCKs ${ }^{1}$, M. CHAFFER $^{1}$ and A. SARAN ${ }^{1}$ \\ Addresses of authors: ${ }^{1}$ National Mastitis Reference Center, Kimron Veterinary Institute, Ministry of \\ Agriculture \& Rural Development, POB 12, Bet Dagan 50250, Israel; ${ }^{2}$ Animal Sciences, Faculty of \\ Agriculture, The Hebrew University of Jerusalem, Rehovot, Israel; ${ }^{3}$ Corresponding author
}

With 2 figures and 1 table

(Received for publication October 5, 1999)

\begin{abstract}
Summary
This study compared the different leucocyte populations in milk from udders infected with different mastitic pathogens and in different stages of infection. Milk samples were collected from quarters free of intramammary infection, acutely infected with Escherichia coli or Staphylococcus aureus and chronically infected with S. aureus, coagulase-negative staphylococci (CNS) or Streptococcus dysgalactiae. Udder bacteriological status was confirmed after three consecutive bacteriological examinations from weekly quarter milk samples. At the time of the trial, milk samples were tested for somatic cell count (SCC) and differential cell count by both light microscopy (LM) and flow cytometry. Monoclonal antibody (mAb) CD11a/CD18 was used in order to differentiate between leucocytes and epithelial cells when tested by flow cytometry. Udder quarters free of intramammary infection had a mean SCC lower than $107 \times 10^{3}$ cells $/ \mathrm{ml}$ in which the epithelial cells were the main cell type followed by polymorphonuclear cells (PMNs), while macrophages and lymphocytes had a lower concentration. Only $56 \%$ of the cells were labelled with the mAb antiCD11a/CD18. In either acute E. coli- or $S$. aureus-infected quarters, SCC were significantly higher $(\mathrm{P}<0.0001)$ than in samples from the time of inoculation, with over $90 \%$ of the cells labelled with the $\mathrm{mAb}$ anti-CD11a/CD18. The main cell type was neutrophils. In chronically infected cows, differences in SCC and in leucocyte patterns were found between infecting pathogens as well as between quarters harbouring the same pathogen. In all the chronically infected quarters, SCC was significantly higher $(\mathrm{P}<0.05)$ than in uninfected ones. The distribution of the leucocyte patterns in the quarters infected with $S$. dysgalactiae did not differ from that in quarters with acute infection with both E. coli and $S$. aureus. In the cows chronically infected with $S$. aureus or CNS, the proportion of PMN was higher but not significantly different from quarters free of intramammary infection, while epithelial cells were significantly lower $(\mathrm{P}<0.05)$. The $\mathrm{T}$ lymphocytes bearing $\mathrm{CD}^{+}{ }^{+}$or $\mathrm{CD}^{+}$were significantly higher in quarters chronically infected with $S$. aureus than in quarters free of intramammary infection and in quarters acutely infected with either E. coli or $S$. aureus. In all samples B cells were negligible.
\end{abstract}

\section{Introduction}

Somatic cell count (SCC) is a widely used marker of udder health and milk quality. In order to study mastitis it is important to acquire information about the specific mastitis pathogen, the pattern of leucocyte populations in the milk and their functions. When pathogens penetrate the teat canal barrier, leucocytes normally nesting in the gland initiate an inflammatory response. In the healthy mammary gland, the predominant cell types are macrophages followed by lymphocytes, polymorphonuclear cells (PMNs) and epithelial cells (Concha et al., 1986; Miller et al., 1990, 1991). If the invading pathogens are not eliminated, leucocytes, primarily neutrophils, are recruited from the blood in sufficient numbers to act against bacterial colon- 
ization of udder tissues. However, pathogens are not eliminated from all infections and thus the event may become a chronic one.

Milk is not the main element in the udder defence mechanisms as leucocytes are also found in the mammary tissues. In addition, the methods used for cell differentiation in milk, light microscopy (LM) (Shoshani et al., 2000) or flow cytometry (Redelman et al., 1988; Saad and Ostensson, 1990; Miller et al., 1993a) preclude defattening of milk. The presumption that some cell types may preferentially attach to fat globules and that their removal might distort the proportions of residual leucocyte population patterns was examined (Dulin et al., 1982). No significant differences were found between the direct smear (whole milk) and the cytospin procedures (defatted milk) when used for the LM, leading to the conclusion that the latter is a suitable method for the study of leucocyte populations in the mammary gland for differential cell counts in milk over a wide range of SCC classes. The identification of leucocytes in blood and milk by a selective set of monoclonal antibodies (mAbs) analysed by flow cytometry is an acceptable method, as tested and published previously (Park et al., 1992).

It was suggested that the type of leucocytes, as well as their numbers and functions, vary among pathogens, stages of the infection and in individual cows. Therefore, differences in leucocyte populations and the dynamics of recruitment and functioning are instrumental in the recovery of the mammary gland from mastitic events. The aim of this study was to compare the different leucocyte populations in milk from udders infected with different mastitic pathogens and through different stages of infection.

\section{Materials and Methods}

\section{Animals}

Israeli-Holstein cows, either free of intramammary infection, artificially infected intramammarily with Escherichia coli or Staphylococcus aureus, or chronically infected with other udder pathogens were included in the study. All cows were in the middle of their second or more lactations and yielding more than 251/day milk. Chronic udder conditions known as chronic were confirmed after three consecutive weekly bacteriological examinations of quarter milk samples. Cows were milked three times daily. Food was offered in mangers located in the sheds.

\section{Study layout}

Thirteen to 31 quarters (one to two per cow) were selected in each of the following categories: (1) 31 quarters free of intramammary infection; (2) 16 quarters acutely infected with E. coli or 24 quarters acutely infected with $S$. aureus; and (3) quarters chronically infected with $S$. aureus (30), coagulase-negative staphylococci (CNS) (29) or Streptococcus dysgalactiae (13). Cows acutely infected with E. coli were sampled $10 \mathrm{~h}$ post-infection (animals were treated at that time) and those infected with $S$. aureus were sampled $24 \mathrm{~h}$ post-infection.

The cows were sampled during the morning milking, quarters were cleaned with tap water, dried with individual towels and disinfected prior to sampling with a non-woven towelette moistened with chlorhexidine, cetrimide and ethanol (Medi-Wipes, AL Baad Messuot Itzhak, Israel) and the first squirts of milk were discarded. For bacteriological testing, approximately $5 \mathrm{ml}$ of milk was taken in a sterile tube. Foremilk $(50 \mathrm{ml})$ was taken at the same time from each quarter, divided into three tubes for the determination of SCC and differential cell count by LM and by flow cytometry.

\section{Antibodies and conjugates}

The mAbs (VMRD Inc., Pullman, WA, USA) used for the detection of different leucocytes were: (1) anti-lymphocyte; anti-CD4 ${ }^{+}$: CACT 138A, anti-CD8 ${ }^{+}$: CACT 80C and two anti-B: GB25A and BAS9A; (2) anti-monocyte/macrophage; BAQ151A; (3) anti-granulocyte; CH138A (G1) and MM20A (G3); (4) anti-CD11a/CD18: BAT75A. All mAbs were species reactive with bovine cells.

The polyclonal antibodies used were goat $\mathrm{F}\left(\mathrm{ab}^{\prime}\right) 2$ anti-mouse $\operatorname{IgG}(\mathrm{H}+\mathrm{l})$ conjugated with fluorescein isothiocyanate (FITC) that exhibited minimal cross-reaction to human, bovine and horse serum proteins (Jackson Immuno Research, West Grove, USA) and goat anti-mouse IgG-1 conjugated with TRI-COLOR affinity isolated (CALTAG Laboratories, Burlingame, CA, USA). 


\section{Bacteriological examinations}

Duplicate quarter foremilk samples were taken aseptically according to accepted standard procedures (International Dairy Federation, 1981) and submitted to the laboratory within $1 \mathrm{~h}$. Bacteriological analysis was performed according to accepted standards (National Mastitis Council, 1987). A volume of $0.01 \mathrm{ml}$ of each milk sample was spread over blood agar plates (Bacto-Agar; Difco Laboratory, Detroit, MI) containing $5 \%$ of washed sheep red blood cells and into MacConkey agar (Difco). All plates were incubated at $37^{\circ} \mathrm{C}$ and examined for growth at 18 and $42 \mathrm{~h}$. Colonies of staphylococci were examined for coagulase production by the tube coagulase test. CNS strains were further identified using the ID 32 Staph (Bio Merieux S.A., Marcy-l'Etoile, France) and the Apilab Plus 1990 computerized recognition systems. Only when the identification percentage exceeded $90 \%$ and $\mathrm{T}>60 \%$, was a bacterial strain specifically named.

\section{Bacteria and inoculation procedure}

Cows were inoculated with either a $S$. aureus strain (V-07) prevailing in the herd or with a E. coli P4 strain (Bramley, 1976). Two diagonally opposing quarters in each cow were intracisternally inoculated with 2000 colony-forming units (cfu) of $S$. aureus or $500 \mathrm{cfu}$ of $E$. coli in $1 \mathrm{ml}$ of pyrogen-free saline. Inoculation was performed with a sterile 18-gauge catheter via the teat canal after completion of milking.

\section{Total cell count}

The SCC was determined with a Coulter cell counter (CC) (Z1 model, Coulter Electronics, Luton, UK).

\section{Immunological assays: LM procedure and flow cytometry}

$L M$ procedure. The LM differential cell count was carried out as described previously (Shoshani et al., 2000) on approximately 100-150 cells. Ten millilitres of the milk sample was centrifuged in a conical tube at $500 \mathrm{~g}$ for $10 \mathrm{~min}$ at $40^{\circ} \mathrm{C}$; the fat layer and supernatant were discarded, and the cell-containing pellet was dispersed in $1 \mathrm{ml}$ of phosphate-buffered saline (PBS). The cell concentration and viability were determined by mixing $10 \mu \mathrm{l}$ of that solution with $10 \mu \mathrm{l}$ of trypan blue $(0.2 \mathrm{~g} / \mathrm{l})$ and counting the stained cells in a haemocytometer. PBS was then added to the cell suspension to produce a final concentration of $5 \times 10^{5}$ cells $/ \mathrm{ml}$. Cell viability was $90 \%$ and higher in all samples. A $0.1 \mathrm{ml}$ volume of the cell suspension was mixed with $0.1 \mathrm{ml}$ of $0.2 \mathrm{~g} / \mathrm{l}$ tripticase soya broth, and $400 \mu \mathrm{l}$ of the final suspension was centrifuged in cytospin tubes at $150 \mathrm{~g}$ for $20 \mathrm{~min}$. A differential count of the cells was carried out after staining with a modified Wright Giemsa stain. Absolute numbers of PMN, macrophages, lymphocytes, eosinophils and epithelial cells were calculated from the total cell count determined by the CC.

Flow cytometry procedure. Milk samples were kept at room temperature and analysed up to $3 \mathrm{~h}$ after collection. Samples were analysed on a FACScan flow cytometer (Becton Dickinson Immunocytometry System, San Jose, CA, USA). The laser beam was set at a wavelength of $488 \mathrm{~nm}$. The number of somatic cells in each sample was determined by CC and the volume of milk containing approximately $1 \times 10^{6}$ cells was split into $15 \mathrm{ml}$ test tubes, one tube for each $\mathrm{mAb}$ and the control. The tubes were centrifuged for $10 \mathrm{~min}\left(230 \mathrm{~g}, 4^{\circ} \mathrm{C}\right)$, the fat was removed by aspiration, the supernatant was discarded and the pellets were resuspended in PBS and washed by centrifugation once more for $5 \mathrm{~min}\left(200 \mathrm{~g}, 4^{\circ} \mathrm{C}\right)$. To each tube (cell pellets), $50 \mu \mathrm{l}$ of one of the mAbs or PBS (as a negative control) was added, mixed gently and incubated for $1 \mathrm{~h}$ at $4^{\circ} \mathrm{C}$. The cells were washed three times in PBS and $50 \mu \mathrm{l}$ of (single) or two (double) of the conjugated antibodies were added, mixed gently and incubated for $30 \mathrm{~min}$ at $4^{\circ} \mathrm{C}$. Following incubation the cells were washed and resuspended in PBS to a final volume of $1 \mathrm{ml}$. To calculate the percentages of the different leucocytes, 10000 events were read per sample. The absolute cell number for each cell type was calculated from the SCC determined by CC. The results are given as the percentage of positive cells labelled by the mAbs (\% POS) and the mean fluorescent canal (MFC) of the positive cells.

\section{Statistical analysis}

Data were analysed using the SAS general linear model (GLM) procedure (SAS, 1990). 


\section{Results}

Leucocyte populations were determined by both LM and flow cytometry in order to increase data reliability. In the flow cytometry method, total leucocyte populations were calculated as the positive cells (labelled) by the CD11a/CD18 mAb. A high correlation was found between the two methods $(r=0.96, P<0.001)$ for total lymphocytes and PMN. Subpopulations of lymphocytes were determined by flow cytometry only. The number of lymphocytes labelled with anti-CD $4^{+}$and anti-CD $8^{+}$was around $87 \%$ of the number counted with the LM. The percentage of lymphocytes defined as $\mathrm{B}$ cells by both $\mathrm{mAbs}$ was negligible. A lower correlation $(\mathrm{r}=0.78, \mathrm{P}<0.03)$ was found between the two methods for macrophages, due to poor binding of BAQ151A mAb, mainly in the uninfected quarters with low SCC, and the difficulty in some samples of identifying macrophages from epithelial cells (LM). In the flow cytometry method, epithelial cells were calculated as the negative cells (not labelled) by the CD11a/CD18 mAb. No significant difference was found in epithelial cells of udder quarters free of intramammary contamination when identified by LM and the CD11a/CD18-negative cells by flow cytometry (44 vs. $45 \%$, respectively) (Table 1). However, the standard deviation found by the LM was significantly larger than that by flow cytometry.

A sample of the different leucocyte populations in milk determined by the flow cytometry method is exhibited in Fig. 1. A histogram pattern of the different leucocytes labelled with the different $\mathrm{mAbs}$ is presented in Fig. $1 \mathrm{a}-\mathrm{d}$. The location of the positive cells labelled with the $\mathrm{mAbs}$ used on the dot plot [forward-angle light scatter (FSC) by logarithm side-light scatter (SSC)] map is presented in Fig. 1e-h.

Udder quarters free of intramammary infection had a SCC lower than $107 \times 10^{3}$ cells $/ \mathrm{ml}$ milk. In these cows, a significant difference $(\mathrm{P}<0.05)$ was found in total lymphocytes and $\mathrm{T}$ lymphocytes bearing $\mathrm{CD}^{+}$or $\mathrm{CD}^{+}$, macrophages, PMN and epithelial cells between cows. However, epithelial cells were the main cell types followed by PMN, while macrophage cells and lymphocytes were in lesser proportions (Table 1).

In both acute E. coli- or S. aureus-infected quarters, SCC were significantly higher $(\mathrm{P}<0.0001)$ from that at the time of inoculation (data not shown). Although the increased SCC was higher in the E. coli-infected cows, the difference was not significant. The main cell type was neutrophils as identified by LM (Table 1). In the flow cytometry method the percentage of PMN labelled by the mAb G1 was significantly lower than the PMN labelled by the $\mathrm{mAb}$ G3 or the neutrophils determined by LM. Milk had $>2 \times 10^{6}$ SCC, $90 \%$ of the total SCC was defined by the LM as neutrophils, but not with the mAbs G1 or G3 as PMN. However, over $90 \%$ of the cells were labelled with the mAb anti-CD11a/CD18. In those samples, only 10$25 \%$ of the cells were labelled with G1 mAb and 60-70\% with G3 but with lower MFC than other samples. Macrophages and lymphocytes bearing $\mathrm{CD}^{+}$or $\mathrm{CD} 8^{+}$were almost not found in the cows infected with $E$. coli, while in the acute infection with $S$. aureus, the proportion remained unchanged. In both E. coli and $S$. aureus acute infections, the absolute number of those mononuclear cells increased due to the elevation in the total somatic cells.

In chronically infected cows, differences in SCC and in leucocyte patterns were found between infecting pathogens as well as between quarters harbouring the same agent (Table 1). In all the chronically infected quarters, the SCC was significantly higher $(\mathrm{P}<0.05)$ than in uninfected ones. In quarters infected with $S$. aureus or S. dysgalactiae, the SCC was higher than in those infected with CNS but the difference was not significant due to a high variation between cows with each infecting agent. The proportion of leucocytes from the SCC as identified by both LM and flow cytometry (CD11/CD18-positive cells) was significantly higher (P > 0.05) in all infected quarters in relation to those free of infection. The distribution of the leucocyte patterns in the quarters infected with $S$. dysgalactiae was not different from the acute infection with both E. coli and $S$. aureus. However, the percentage of neutrophils identified by LM and those labelled by both G1 and G3 mAbs were not different (Table 1). In the cows chronically infected with $S$. aureus and CNS, the proportion of PMN was higher, but not significantly different from quarters free of intramammary infection, while epithelial cells were significantly lower $(\mathrm{P}<0.05)$. Lymphocytes bearing $\mathrm{CD}^{+}$or $\mathrm{CD}^{+}$were significantly higher in quarters chronically infected with $S$. aureus than in quarters free of intramammary infection and in quarters acutely infected with $E$. coli or $S$. aureus. 
Table 1. Mean \pm standard error (SE) of somatic cell count (SCC) and proportion (\%) of neutrophils counted by light microscopy (LM), PMN labelled by monoclonal antibody (mAb) (G1), macrophage lymphocytes bearing $\mathrm{CD}^{+}{ }^{-}$or $\mathrm{CD}^{+}$labelled by the different mAbs, and epithelial cells as calculated as CD18 (flow cytometry) and those counted by LM, in milk from free or infected quarters with different pathogens

\begin{tabular}{|c|c|c|c|c|c|c|c|c|c|c|c|}
\hline Condition & & $\begin{array}{l}\text { No. of } \\
\text { quarters }\end{array}$ & SCC $\times 1000$ & $\begin{array}{l}\text { Neutrophils } \\
\text { (LM) }\end{array}$ & $\begin{array}{l}\text { PMN } \\
\text { (G1) }\end{array}$ & Macrophages & $\mathrm{CD}^{+}$ & $\mathrm{CD} 8^{+}$ & $\mathrm{CD}_{18}{ }^{+}$ & $\left(\mathrm{CD} 18^{-}\right)$ & $\begin{array}{l}\text { Epithelial cells } \\
\text { (LM) }\end{array}$ \\
\hline Free & & 31 & $67 \pm 6^{\mathrm{A}}$ & $29 \pm 5$ & $28 \pm 3$ & $13 \pm 2$ & $3.4 \pm 2$ & $7.6 \pm 2$ & $56 \pm 6$ & $44 \pm 5$ & $45 \pm 25$ \\
\hline \multirow[t]{2}{*}{ Acute } & E. coli & 16 & $2752 \pm 349^{\mathrm{C}}$ & $86 \pm 2$ & $38 \pm 6$ & $4 \pm 2$ & $0 \pm 0$ & $0.6 \pm 0$ & $93 \pm 1$ & $7 \pm 2$ & $3 \pm 1$ \\
\hline & S. aureus & 24 & $1521 \pm 262^{\mathrm{BC}}$ & $81 \pm 4$ & $36 \pm 6$ & $11 \pm 2$ & $2.4 \pm 1$ & $2.9 \pm 1$ & $89 \pm 4$ & $10 \pm 5$ & $2 \pm 3$ \\
\hline \multirow[t]{3}{*}{ Chronic } & S. aureus & 30 & $723 \pm 221^{\mathrm{BC}}$ & $41 \pm 5$ & $42 \pm 6$ & $17 \pm 1$ & $14 \pm 4$ & $23 \pm 5$ & $89 \pm 5$ & $11 \pm 5$ & $6 \pm 3$ \\
\hline & CNS & 29 & $320 \pm 74^{\mathrm{B}}$ & $52 \pm 7$ & $49 \pm 3$ & $13 \pm 2$ & $9 \pm 1$ & $9 \pm 2$ & $77 \pm 4$ & $21 \pm 7$ & $11 \pm 3$ \\
\hline & S. dysgalactiae & 13 & $809 \pm 267^{\mathrm{BC}}$ & $74 \pm 5$ & $73 \pm 6$ & $5 \pm 2$ & $3 \pm 1$ & $5 \pm 1$ & $86 \pm 5$ & $14 \pm 5$ & $7 \pm 3$ \\
\hline
\end{tabular}

${ }^{1}$ Bacterial contamination and clinical condition.

${ }^{\mathrm{A}-\mathrm{C}}$ Means within a column with different superscripts differ significantly $(\mathrm{P}<0.05)$.

CNS, coagulase-negative staphylococci. 

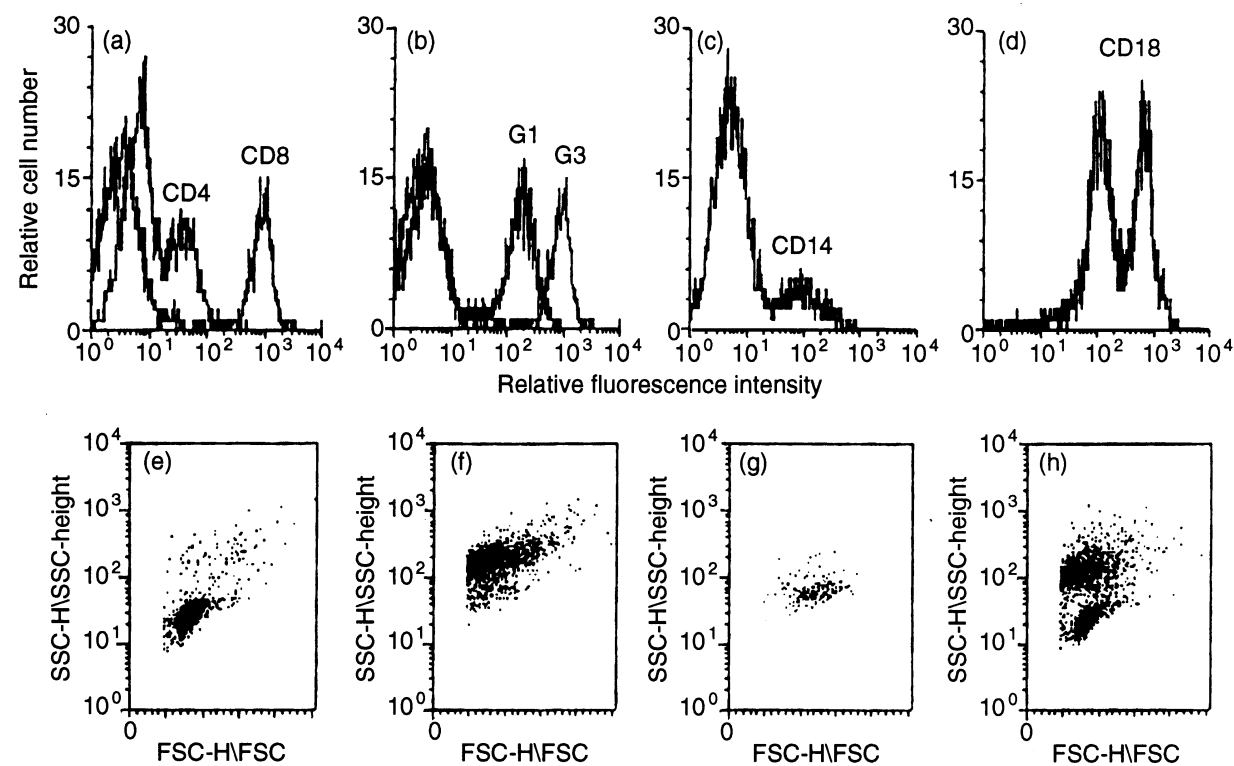

Fig. 1. Histogram fluorescence analysis of milk leucocytes (a-d) and dot plot of forward-angle light scatter (FSC) vs. logarithm side-light scatter (SSC) (e-h) of the leucocyte map. (a, e) Lymphocytes labelled with monoclonal antibodies (mAbs) anti-CD4 ${ }^{+}$or $\mathrm{CD}^{+}$; (b, f) PMN labelled with mAbs G1 or G3; (c, g) macrophages labelled with $\mathrm{mAb}$ anti-CD14; $(\mathrm{d}, \mathrm{h})$ leucocytes labelled with $\mathrm{mAb}$ anti-CD11a/CD18.

Examples of different leucocyte populations in milk from quarters free of intramammary infection (Fig. 2a, b), acute infection with E. coli (Fig. 2c, d) and chronic infection with S. aureus are exhibited in Fig. 2. In uninfected glands, only a small percentage of the cells were labelled with the CD11a/CD18 mAb $(13+13.2=26.2 \%)$ (Fig. $2 \mathrm{~b})$. Of those positive cells, all of the lymphocytes were also positive to $\mathrm{CD} 4^{+}$or $\mathrm{CD} 8^{+} \mathrm{mAb}$ (double positive, data not shown) but only a small percentage of the cells appeared in the PMN area (FSC by SSC) (Fig. 2a) and those were also positive to the $\mathrm{G} 1 \mathrm{mAb}$. In uninfected glands, most of the cells $(72.7 \%)$ were negative for all $\mathrm{mAbs}$ used. In the glands acutely infected with E. coli (Fig. 2c, d), most of the cells were in the PMN area (Fig. 2c) and were labelled by both G1 and CD11a/CD18 mAbs (86.8\%). In glands chronically infected with $S$. aureus (Fig. 2e-g), a high percentage of the cells were in the lymphocyte area (Fig. 2e) and all of those cells were labelled by the CD11a/CD18 mAb (54.6\%). As for the cells in the PMN area, most cells were double positive.

\section{Discussion}

The CD11a/CD18 receptors are distributed on T, B and NK cells, macrophages and granulocytes (Larson and Springer, 1990), but not on epithelial cells. In this study, epithelial cells were the main type found in the quarters free of intramammary infection, identified by LM and by flow cytometry as the negative cells to the mAb anti-CD11a/CD18 receptor. However, the standard deviation of the epithelial cells in the LM identification was significantly larger than that found by flow cytometry. This could derive from the difficulty in the identification of epithelial cells from macrophages as reported by Schalm et al. (1971). Therefore, it is probable that by differentiation of milk leucocytes with LM, some of the epithelial cells were counted as macrophages. Macrophages in the milk of these quarters were up to $17 \%$ in both methods. This percentage in milk from cows free of intramammary infection is in agreement with that found by Park et al. (1992) in cows during early and late lactation identified by 

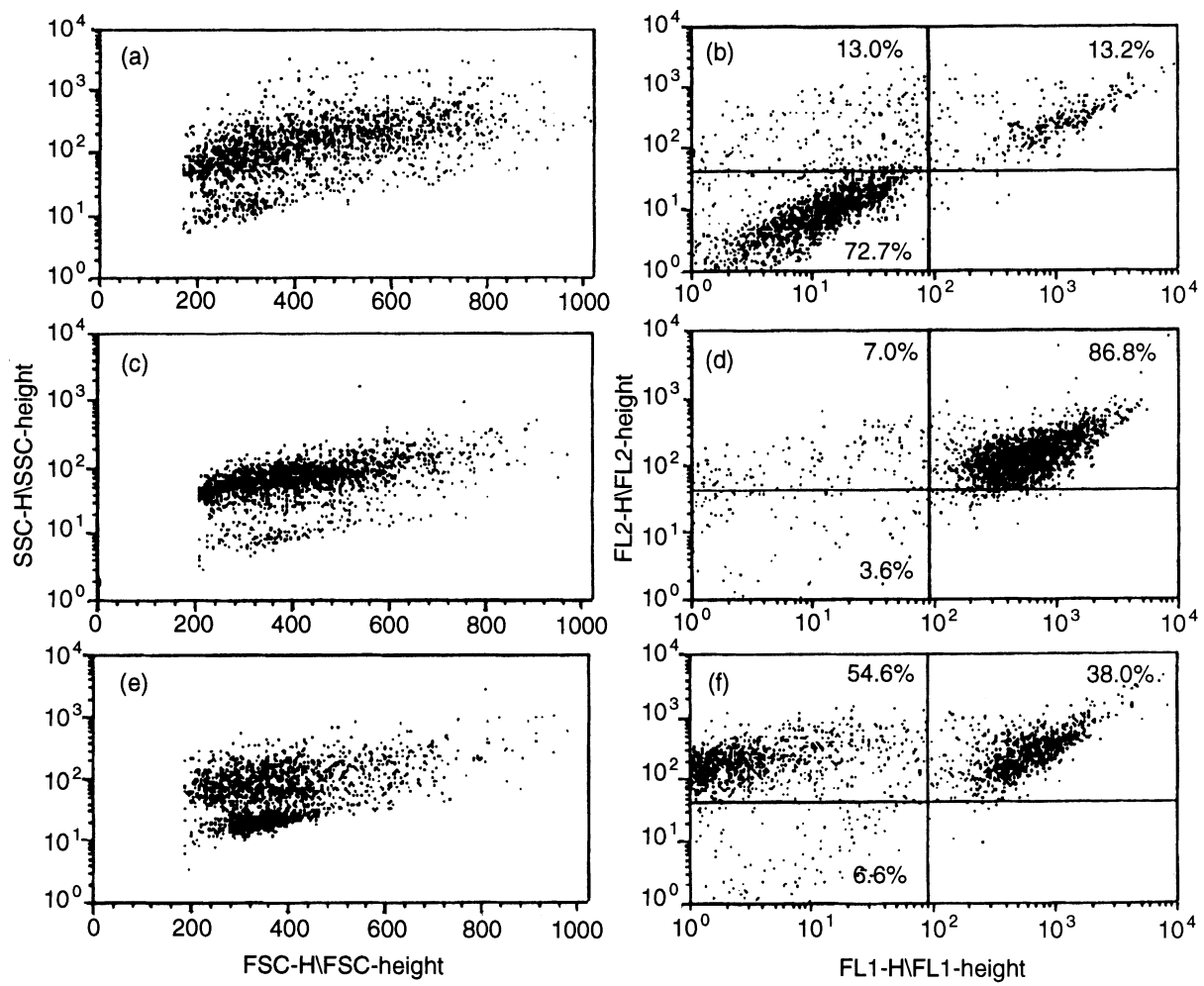

Fig. 2. Dot plot map of leucocyte forward-angle light scatter (FSC) vs. logarithm side-light scatter (SSC) (a, c, e) and fluorescence analysis of milk leucocytes (b, d, f) labelled with monoclonal antibodies (mAbs) anti-PMN (FL1) vs. anti-CD11a/CD18 (FL2). (a, b) Uninfected healthy mammary gland; (c, d) glands acutely infected with Escherichia coli; (e, f) glands chronically infected with Staphylococcus aureus.

flow cytometry. However, other studies using flow cytometry report different results with macrophages being the main cell type with up to $\pm 60 \%$ of the total somatic cells in the milk (Concha et al., 1986; Miller et al., 1990, 1991, 1993b). Although in all of these studies flow cytometry was used to identify the cell types, the differences in the percentages of macrophages in uninfected normal milk could derive from the different animals used and/or the different mAbs used. Therefore, it is suggested that by using mAb to the CD11a/CD18 receptor, it is possible to differentiate between leucocytes and non-immune cells in milk and in particular using this $\mathrm{mAb}$ with other $\mathrm{mAbs}$ specific to the different leucocytes (double labelling) the reliability of the identification increases.

The rapid increase in SCC in both E. coli and $S$. aureus acute infection was mainly due to PMN, while in S. aureus, mononuclear cells, lymphocytes and macrophages, also increased in their absolute number. All those leucocytes were also labelled by the CD11a/CD18 mAb (double positive). However, the MFC of the cells was not different from that of the uninfected milk. The essential role of the CD11a/CD18 receptors as adherence molecules is well documented (Tizard, 1996). Normally, neutrophils float freely in the blood and do not bind to endothelial cells. As a result of bacteria or their products, surface expression of the integrin CD11a/CD18 increased, therefore the assay was not sensitive enough to detect a change in the density of this receptor on the cell surface. It is possible that the neutrophils in the healthy mammary gland also increased those surface receptors before migration to the milk. One of 
the interesting findings is that in the first hours post-inoculation, leucocytes identified by the LM as neutrophils were poorly labelled by the mAb G1. The low percentage of the PMN that were labelled by the mAb G1 during the first hours after inoculation may be the result of downregulation of the receptor on the cell surface (Burton and Kehrli, 1995). This receptor may be of importance in the activity of the PMN in the mammary gland, although this receptor was not given CD designation (Veterinary Medical Research and Development (VMRD), personal communication).

In the mammary glands chronically infected with $S$. aureus or CNS, the SCC were significantly higher $(\mathrm{P}<0.05)$ than in milk from uninfected glands. The cell number of $\mathrm{CD}^{+}$and $\mathrm{CD} 8{ }^{+} \mathrm{T}$ lymphocytes, macrophages increased. However, the proportion significantly increased only in those infected with $S$. aureus and only those bearing T lymphocytes $\mathrm{CD} 4^{+}$or $\mathrm{CD} 8{ }^{+}$. In the milk of quarters chronically infected with $S$. dysgalactiae, the SCC as well as the leucocyte population patterns were more closely related to the acute infection than to the chronic one. Although the presence or absence of granulomas in the chronically infected cows in this study is not known, the significant increase in macrophages and $\mathrm{CD}^{+}$or $\mathrm{CD}^{+} \mathrm{T}$ lymphocytes expressing the integrin CD11a/CD18 indicate the continuous arrival of new cells from the blood into the milk. Moreover, the high proportion of neutrophils in the S. dysgalactiae-infected glands rather than macrophages and lymphocytes, may indicate that the development of granulomas is lower than in S. aureus-infected mammary glands. The lack of B lymphocytes in any of the milk samples is not in agreement with a previous report (Concha et al., 1978; Park et al., 1992). In Park et al. (1992) the percentage of B lymphocytes in late lactation of mammary free of infection was the lowest during the lactation and the drying off period exceeding $6.8 \%$. Therefore it is possible that some of the non-T lymphocytes were B lymphocytes at least in the milk from udders free of infection and those cells were not labelled by the mAbs due to downregulation of the receptors. However, the percentage of lymphocytes labelled by the anti$\mathrm{CD}^{+}$and $\mathrm{CD}^{+} \mathrm{mAbs}$ were also labelled by the anti-CD11a/CD18 mAb, suggesting that $\mathrm{B}$ lymphocytes, if indeed present in the milk, are not a major cell type. The results of this study reinforce the existence of a correlation between the immune response and mammary gland infection while at the same time showing the differences between the different mastitic pathogens and the importance of studying the particular leucocyte population patterns for each one.

\section{References}

Bramley, A. J., 1976: Variations in the susceptibility of lactating and non-lactating bovine udders to infection when infused with Escherichia coli. J. Dairy Res. 43, 205-211.

Burton, J. L., and M. E. Kehrli, 1995: Regulation of neutrophil adhesion molecules and shedding of Stapbylococcus aureus in milk of cortisol- and dexamethasone-treated cows. Am. J. Vet. Res. 56, 9971006.

Concha, C., O. Holmberg, and G. Astrom, 1986: Cells found in non-infected and Staphylococcus-infected bovine mammary quarters and their ability to phagocytose fluorescent microspheres. Z. Vet.-Reihe B. 33, 371-378.

Concha, C., O. Holmberg, and B. Morein, 1978: Proportion of B and T lymphocytes in normal bovine milk. J. Dairy Res. 45, 287-290.

Dulin, A. M., M. J. Paape, and B. T. Weinland, 1982: Cytospin centrifuge in differential counts of milk somatic cells. J. Dairy Sci. 65, 1247-1251.

International Dairy Federation, 1981: Laboratory methods for use in mastitis work, Document 132, Brussels, Belgium.

Larson, R. S., and T. A. Springer, 1990: Structure and function of leukocyte integrins. Immunol. Rev. 114, 181-217.

Miller, R. H., M. J. Paape, R. Filep, and S. Link, 1993a: Flow cytometric analysis of neutrophils in cows' milk. Am. J. Vet. Res. 54, 1975-1979.

Miller, R. H., M. J. Paape, and L. A. Fulton, 1991: Variation in milk somatic cells in heifers at first calving. J. Dairy Sci. 74, 3782-3790.

Miller, R. H., M. J. Paape, L. A. Fulton, and M. M. Schutz, 1993b: The relation of milk somatic cell count to milk yields for Holstein heifers after first calving. J. Dairy Sci. 76, 728-733.

Miller, R. H., M. J. Paape, R. R. Peters, and M. D. Young, 1990: Total and differential somatic cell counts 
and $\mathrm{N}$-acetyl- $\beta$-D-glucosaminidase activity in mammary secretions during dry period. J. Dairy Sci. 73, 1751-1755.

National Mastitis Council, 1987: Laboratory and Field Hand Book on Bovine Mastitis. W.H. Hoard \& Sons, Fort Atkinson, WI.

Park, H. Y., L. K. Fox, M. J. Hamilton, and W. C. Davis, 1992: Bovine mononuclear leukocyte subpopulation in peripheral blood and mammary gland secretion during lactation. J. Dairy Sci. 75, 9981006.

Redelman, D., S. Butler, J. Robison, and D. Garner, 1988: Identification of inflammatory cells in bovine milk by flow cytometry. Cytometry $9,463-468$.

Saad, A., and K. Ostensson, 1990: Flow cytofluorometric studies on the alteration of leukocyte populations in blood and milk during endotoxin-induced mastitis in cows. Am. J. Vet. Res. 51, 1603-1607.

SAS, 1990: SAS/STAT ${ }^{\circledR}$ User's Guide, Version 6, 4th edn, Vol. 2. SAS Institute, Cary, NC.

Schalm, D. W., E. J. Carroll, and N. C. Jaim, 1971: Bovine Mastitis, Chapter 6, pp. 94-127. Lea \& Febiger, Philadelphia.

Shoshani, E., G. Leitner, B. Hanochi, A. Saran, Y. N. Shpigel, and A. Berman, 2000: Mammary infection with Staphylococcus aureus in cows: progress from inoculation to chronic infection and its detection. J. Dairy Res. in press.

Tizard, R. I., 1996: Veterinary Immunology, Chapter 5, pp. 43-54. W.B. Saunders, Philadelphia. 